\title{
OPEN Tetramethylguanidine-f unctionalized melamine as a multifunctional organocatalyst for the expeditious synthesis of 1,2,4-triazoloquinazolinones
}

\author{
Mahnoush Keshavarz ${ }^{1}$, Mohammad G. Dekamin ${ }^{2 \bowtie}$, Manouchehr Mamaghani ${ }^{3 凶}$ \& \\ Mohammad Nikpassand ${ }^{1}$
}

Novel nano-ordered 1,1,3,3-tetramethylguanidine-functionalized melamine (Melamine@TMG) organocatalyst was prepared and adequately identified by various techniques including FTIR, EDX, XRD and SEM spectroscopic or microscopic methods as well as TGA and DTG analytical methods. The Melamine@TMG, as an effective multifunctional organocatalyst, was found to promote smoothly the three-component synthesis of 1,2,4-triazoloquinazolinone derivatives using cyclic dimedone, 3-amino-1,2,4-triazole and different benzaldehyde derivatives in $\mathrm{EtOH}$ at $40^{\circ} \mathrm{C}$. This practical method afforded the desired products in high to excellent yields (86-99\%) and short reaction times (10-25 min). The main advantages of this new method are the use of heterogeneous multifunctional nanocatalyst, simple work-up procedure with no need for chromatographic purification, highly selective conversion of substrates and recyclability of the catalyst, which could be used in five consecutive runs with only a small decrease in its activity.

The discovery of efficient catalytic systems for synthetic chemical reactions is a milestone and key principle in green and sustainable chemistry, which has emerged as an active area of research. Organocatalysis is one of the most popular and rapidly growing research fields since its fundamental "renaissance" at the beginning of the twenty-first century ${ }^{1-12}$. Organocatalytic systems are generally homogenous in nature ${ }^{2,3,11-13}$. However, when they are changed into nano-ordered systems it has been proven to possess heterogeneous catalytic behaviour. This may lead to the designing and exploration of new carbonaceous materials which itself is a hot topic in both academia and industry ${ }^{14-21}$. In addition, a high surface to volume ratio is leading to high activity, selectivity, and often more stability. Nano-ordered organocatalysts can reduce the temperature and the amount of hazardous waste in chemical transformations, and by enhancing the selectivity of a reaction avoid undesired products as well as be simply recovered from the crude products and reused in multiple reactions. Therefore, heterogeneous organocatalysts have resulted in higher yields and cleaner synthesis ${ }^{22-33}$. In this regard, 1,3,5-triazine-2,4,6-triamine is an appropriate choice for designing new heterogeneous organocatalysts by anchoring proper organic molecules to its surface in order to produce multifunctional catalytic systems. 1,3,5-triazine-2,4,6-triamine, namely melamine or cyanuramide, is symmetric heterocyclic base and has been widely used in different industries such as plastics, resins, fertilizers, and insecticides ${ }^{34}$. Furthermore, the various catalysts consist of functionalized melamine have been reported for the synthesis of heterocyclic scaffolds having nitrogen, oxygen, or sulfur in their structures. In fact, melamine-based catalytic systems promote organic transformations smoothly, and hence are more environment friendly and cost-effective ${ }^{19,35-43}$. On the other hand, guanidine and its derivatives have been used, as homogeneous bifunctional organocatalysts, in different organic transformations in recent years ${ }^{4,5,44-50}$. Therefore, designing and exploration of new heterogeneous organocatalytic systems based on melamine and guanidine derivatives would be very desirable.

\footnotetext{
${ }^{1}$ Department of Chemistry, Faculty of Basic Sciences, Rasht Branch, Islamic Azad University, P.O. Box 41335-3516, Rasht, Iran. ${ }^{2}$ Department of Chemistry, Iran University of Science and Technology, 16846-13114 Tehran, Iran. ${ }^{3}$ Department of Chemistry, Faculty of Sciences, University of Guilan, P.O. Box 41335-1914, Rasht, Iran. ${ }^{凶}$ email: mdekamin@iust.ac.ir; m-chem41@guilan.ac.ir
} 
<smiles>Nc1nc(N)nc(N)n1</smiles>

(I)<smiles>[2H]N(CCCN=C(N(C)C)N(C)C)c1nc(N(C)C)nc(N(P)CCCN(C)C(=N)N(C)C)n1</smiles>

Melamine@TMG (1)
1) US, Toluene $10 \mathrm{~min}, \mathrm{rt}$

2) $\mathrm{TMG}, \mathrm{Et}_{3} \mathrm{~N}, \mathrm{KI}$, Reflux $72 \mathrm{~h}$ under $\mathrm{N}_{2}$

3) Drying at $60{ }^{\circ} \mathrm{C}$

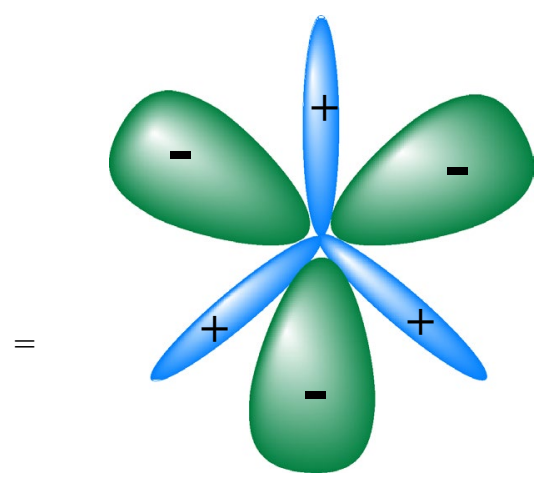<smiles>CC1(C)CC(=O)CC(=O)C1</smiles>

2<smiles>Nc1nc[nH]n1</smiles>

3

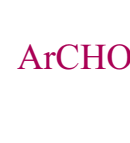

4<smiles>CC1(C)CC(=O)C2=C(C1)Nc1ncnn1C2Br</smiles>

5

Scheme 1. Preparation of nano-ordered multifunctional Melamine@TMG organocatalyst and its application for the three-component synthesis of 1,2,4-triazoloquinazolinones $\mathbf{5 a - j}$.

Quinazolinone derivatives have received considerable attention as a well-known family of $N$-containing heterocyclic scaffolds in medicinal chemistry. They possess significant biological and medicinal properties such as antimicrobial ${ }^{51,52}$, anticonvulsant ${ }^{53}$, antihistaminic ${ }^{54}$, antihypertensive ${ }^{55}$, etc. Among various reported procedures for the synthesis of 1,2,4-triazoloquinazolinone derivatives, the three-component reaction of enolizable 1,3-dicarbonyls, 3-amino-1,2,4-triazole, and aldehydes/ketones has been known as the most beneficial method in terms of obtained yield, selectivity and green chemistry principles ${ }^{51,56-66}$. Some recent examples include DABCO based ionic liquid ${ }^{67}, \mathrm{TiO}_{2}$ nanoparticles supported ionic liquids ${ }^{68}$, magnetic nanoparticles coated by silica with bis dicationic bridge ${ }^{69}$, sulfonic acid functionalized SBA- $15^{70}$, nanoporous silica ${ }^{71}, \mathrm{H}_{4}\left[\mathrm{~W}_{12} \mathrm{SiO}_{40}\right]$ grafted on magnetic chitosan ${ }^{72}, \mathrm{~L}$-proline ${ }^{51}$, $p$-toluenesulfonic acid monohydrate ${ }^{73}$, sulfamic acid ${ }^{74}$, anthranilic acid $^{75}$, molecular iodine $^{76}$, etc $\mathrm{c}^{77,78}$. However, there is a lot more room to explore new and more efficient catalytic systems for this MCR which can work under green conditions using organocatalytic systems.

In this present work, we hereby report a green approach for the synthesis of 1,2,4-triazoloquinazolinones catalyzed by the 1,1,3,3-tetramethylguanidine superbase ${ }^{79}$ anchored onto melamine (Melamine@TMG, 1) as a novel nano-ordered multifunctional and heterogeneous organocatalyst (Scheme 1). The Melamine@TMG catalyst was prepared in two definite steps: The melamine surface modification with 3-bromopropyl groups was the first step to afford Melamine@PrBr intermediate $(\mathbf{I})^{41}$; the second step was functionalization of the obtained Melamine@PrBr nanoparticles with the TMG base through bimolecular nucleophilic substitution $\left(\mathrm{S}_{\mathrm{N}} 2\right)$. The obtained nanocatalyst was characterized by different spectroscopic, microscopic, and analytical techniques. The efficiency of the Melamine@TMG nanocatalyst was examined in the synthesis of 1,2,4-triazoloquinazolinones. After completion of reactions, the Melamine@TMG nanocatalyst was separated from the crude products by washing in EtOH during crystallization of the desired products and exhibited the best catalytic performance in the first cycle (98\% isolated product) and it's activity decreased slightly after four times of recycling ( $84 \%$ isolated product). 
(a)

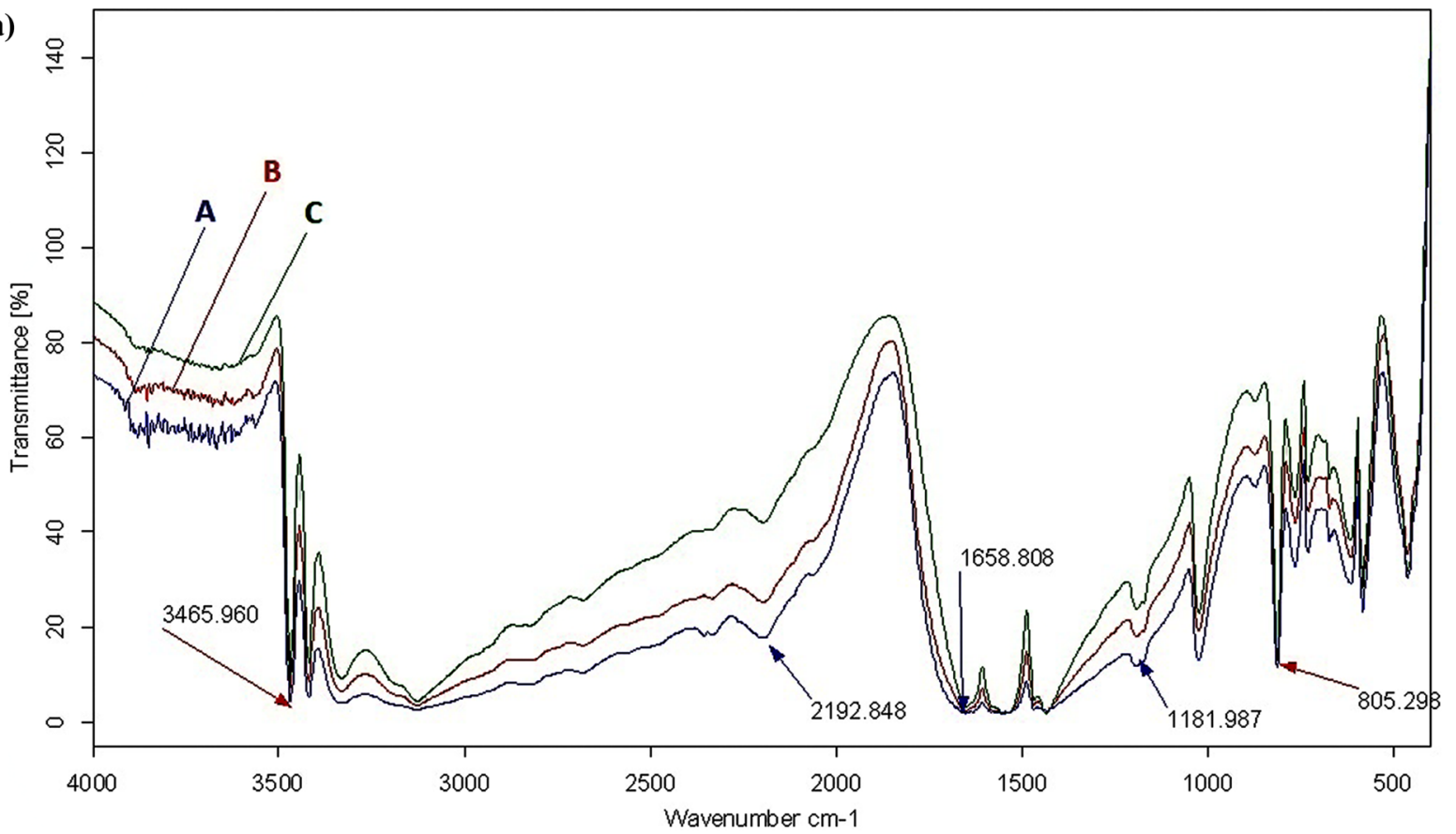

(b)

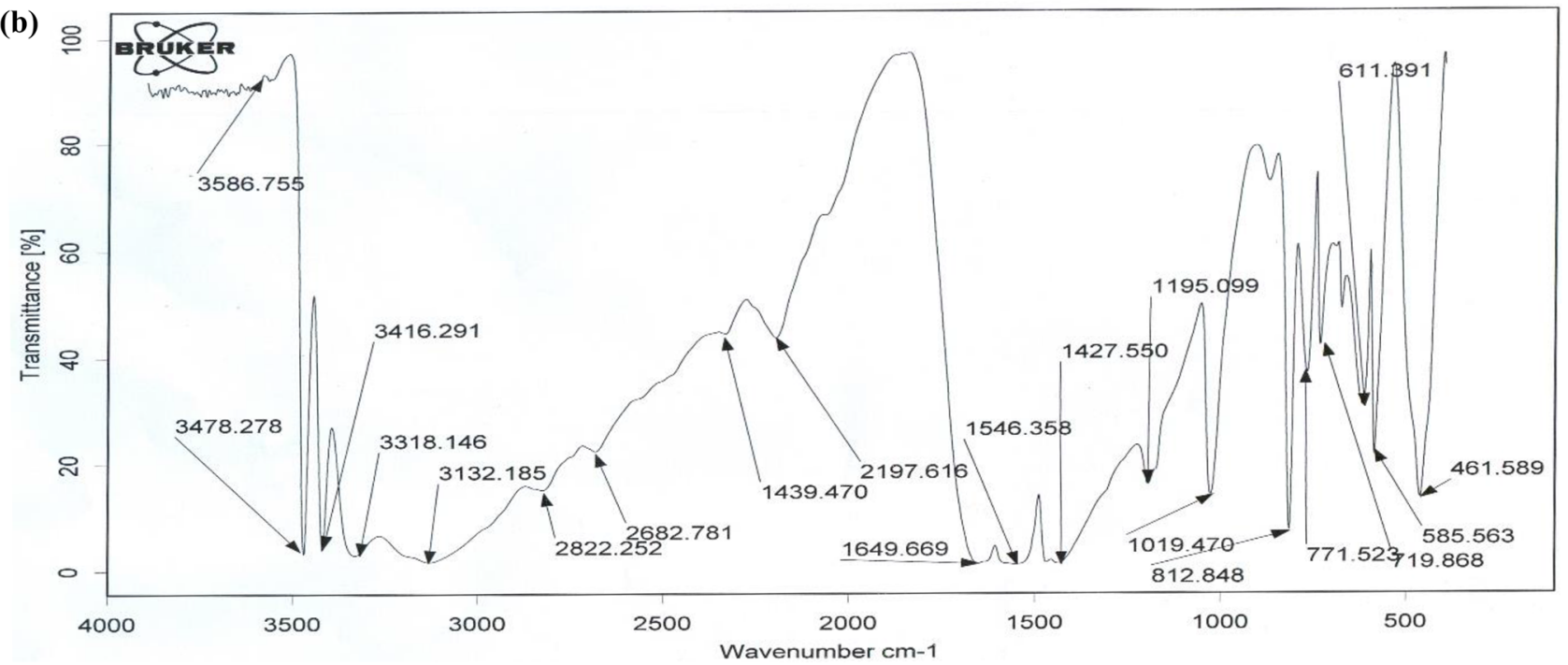

Figure 1. FTIR spectra of melamine (A), the Melamine@PrBr (B), and the nano-ordered Melamine@TMG (1, C, part a) and the recycled Melamine@TMG catalyst after five consecutive runs in the model reaction (part b).

\section{Experimental}

Materials and instruments. All chemicals, reagents, and solvents were supplied by Merck, Sigma-Aldrich, or local Companies and used as received, except for benzaldehyde which a fresh-distilled sample was used. X-ray diffraction (XRD) patterns were obtained using an X'Pert PRO MPD PANalytical Company. The infrared spectra of the catalyst and products were measured by a Bruker-Vector 33 Fourier transform infrared spectrometer (FTIR) using $\mathrm{KBr}$ discs. Scanning electron microscopy (SEM) and energy-dispersive X-ray (EDX) analysis were carried out on a TESCAN-Mira III. The thermogravimetric analysis (TGA) and derivative thermogravimetric (DTG) curves were determined on a TGA/DSC Mettler Toledo apparatus. ${ }^{1} \mathrm{H}$ and ${ }^{13} \mathrm{C}$ nuclear magnetic resonance (NMR) spectra were recorded on a Bruker AVANCE 500 in DMSO- $d_{6}$ at ambient temperature. The CHN analysis were measured by a Thermo Scientific Eager 800. All compounds, except $\mathbf{5} \mathbf{c}$ and $\mathbf{5 i}$, are known and their structures were confirmed by comparison of their melting points as well as FTIR and ${ }^{1} \mathrm{H}$ NMR spectral data with the authentic samples (Supplementary Information).

Preparation of the Melamine@TMG catalyst (1). Preparation of $\mathbf{N}^{2}, \boldsymbol{N}^{4}, \boldsymbol{N}^{6}$-tris(3-bromopropyl)-1,3,5 -triazine-2,4,6-triamine (Melamine@PrBr, I). Melamine (10 mmol, $1.261 \mathrm{~g}$ ) was dispersed in EtOH (150 mL) by sonication for $10 \mathrm{~min}$. Then, the obtained mixture was transferred into a round bottom flask and 1,3-di- 


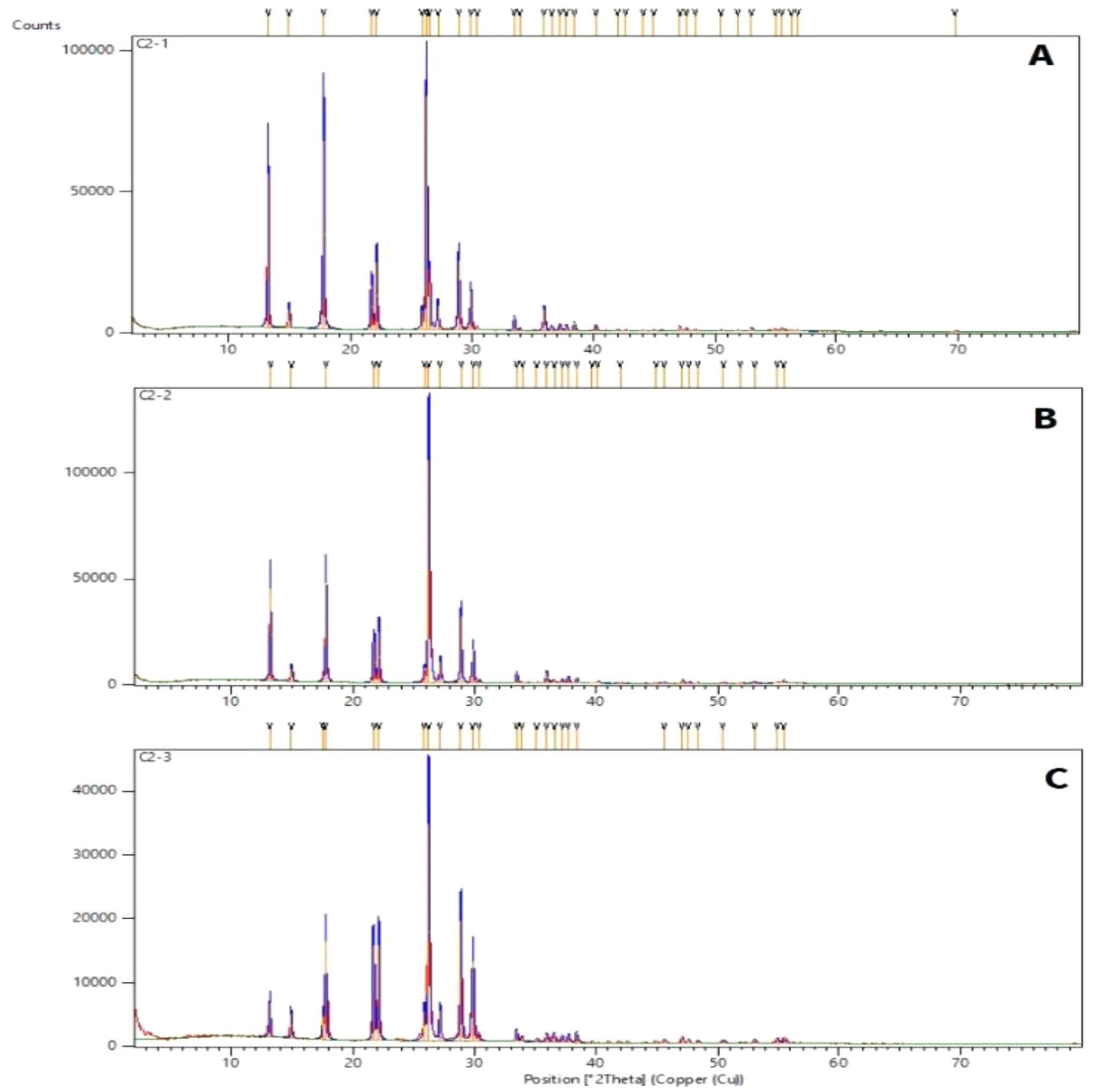

Figure 2. XRD patterns of the melamine (A), the Melamine@PrBr (B), and the nano-ordered Melamine@TMG $(1, \mathrm{C})$.

bromopropane $\left(29.4 \mathrm{mmol}, \mathrm{d}=1.98 \mathrm{~g} . \mathrm{cm}^{-3}, 3.0 \mathrm{~mL}\right.$ ) was added ${ }^{41}$. The obtained colloidal mixture was heated at $60{ }^{\circ} \mathrm{C}$ under stirring by a mechanical stirrer $(400 \mathrm{rpm})$ for $24 \mathrm{~h}$. Afterward, the reaction mixture was filtered off and the white solid was washed twice with hot EtOH and dried under vacuum to afford Melamine@PrBr $(\mathbf{I})$ in $96 \%$ yield.

Preparation of 1,1,3,3-tetramethylguanidine-functionalized melamine nanocatalyst (Melamine@TMG, 1). The as-prepared Melamine@PrBr $(1.2 \mathrm{~g})$ was dispersed in dry toluene $(150 \mathrm{~mL})$ in a round-bottom flask by ultra-

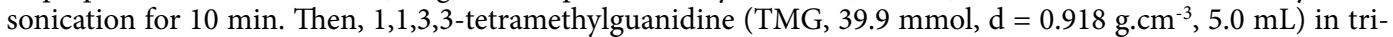
ethylamine $\left(79 \mathrm{mmol}, \mathrm{d}=0.73 \mathrm{~g} . \mathrm{cm}^{-3}, 11 \mathrm{~mL}\right)$ and $\mathrm{KI}(1.2 \mathrm{mmol}, 0.02 \mathrm{~g})$ were added to the obtained mixture under mechanical stirring $(400 \mathrm{rpm})$. The reaction mixture was then heated under $\mathrm{N}_{2}$ atmosphere for $72 \mathrm{~h}$ and the final product was filtered off and washed twice with $\mathrm{EtOH}$ and dried at $60{ }^{\circ} \mathrm{C}$ under vacuum for $2 \mathrm{~h}$ to afford the Melamine@TMG, as a white solid, in 91\% yield. 
(a)

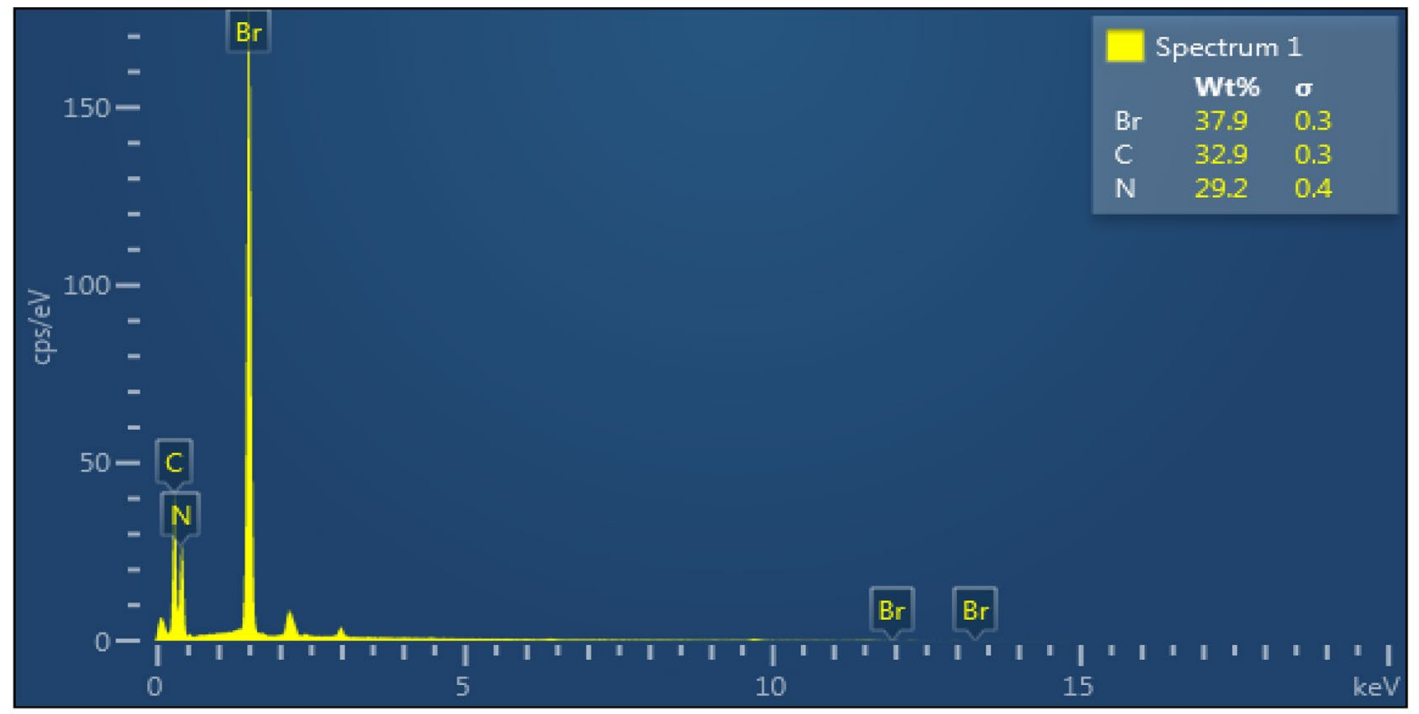

(b)

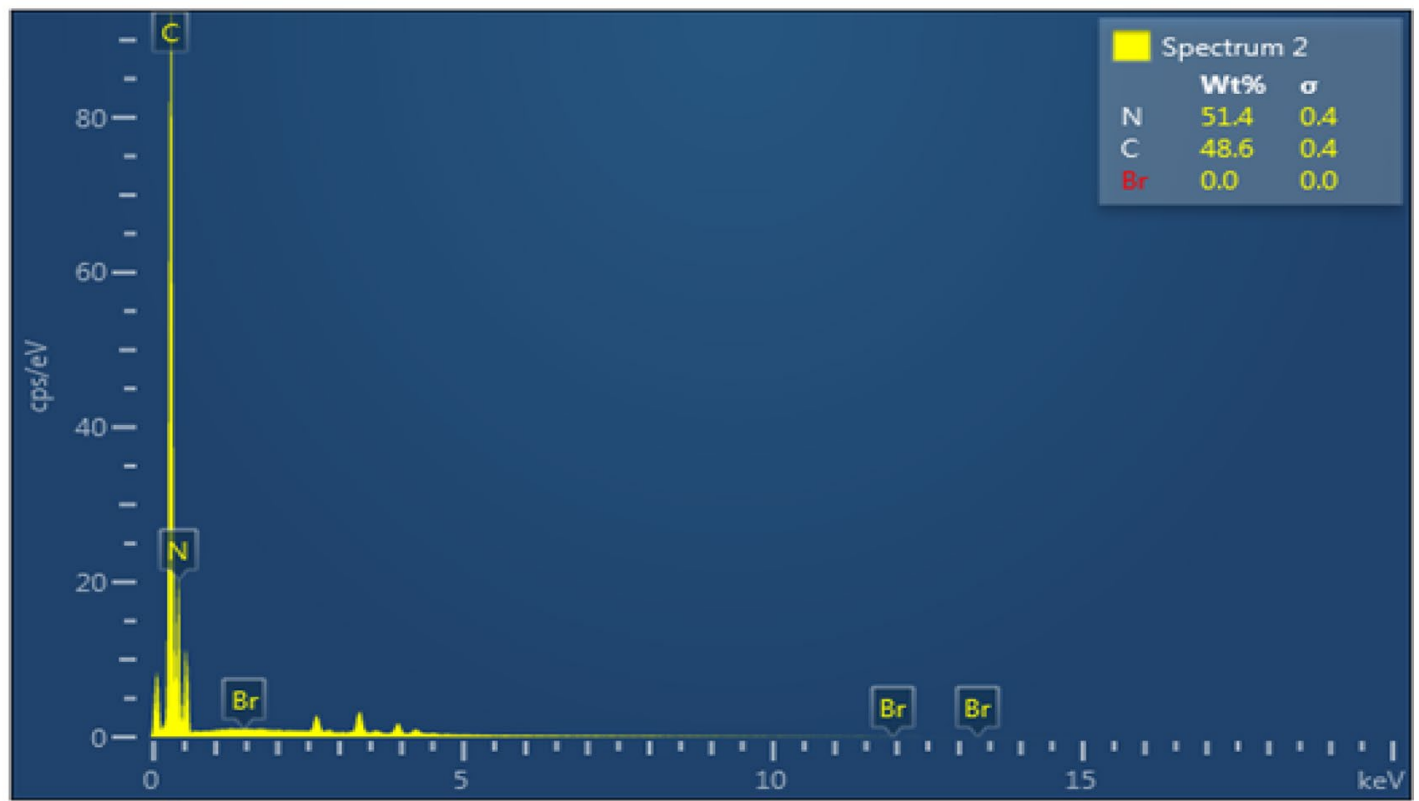

Figure 3. The EDX spectra of the Melamine@PrBr $(\mathbf{a})$ and nano-ordered Melamine@TMG $(\mathbf{1}, \mathbf{b})$.

General procedure for the synthesis of 1,2,4-triazoloquinazolinones $5 a-j$ catalyzed by Melamine@TMG (1). To a mixture of dimedone (2,1 mmol, $0.140 \mathrm{~g}), 3$-amino-1,2,4-triazole $(3,1 \mathrm{mmol}, 0.084 \mathrm{~g})$ and arylaldehyde $(4,1 \mathrm{mmol})$ in EtOH (3 mL), Melamine@TMG $(1,2.5 \mathrm{~mol} \%, 15 \mathrm{mg})$ was added. The reaction mixture was stirred at $40{ }^{\circ} \mathrm{C}$ for times mentioned in Table 2 and the progress of the reaction was observed by TLC. After completion of the reaction, a precipitate was formed which was dissolved in additional $\mathrm{EtOH}(3 \mathrm{~mL})$ by heating and filtered off to separate the catalyst 1 . The filtrate was allowed to stand at room temperature to give pure products $\mathbf{5 a}-\mathbf{j}$. The separated catalyst was then washed with EtOAc and $n$-hexane $(2 \mathrm{~mL})$ for $10 \mathrm{~min}$., respectively, and finally dried at $60^{\circ} \mathrm{C}$ under vacuum for $0.5 \mathrm{~h}$ to be used for further next runs.

\section{Results and discussion}

Characterization of the nano-ordered Melamine@TMG organocatalyst (1). The as-prepared nano-ordered multifunctional and heterogeneous Melamine@TMG organocatalyst (1) was properly characterized by Fourier transform infrared (FTIR) and energy dispersive X-Ray (EDX) spectroscopy, X-ray diffraction (XRD), scanning electron microscopy (SEM), and thermal gravimetric analysis (TGA) and derivative thermogravimetry (DTG) techinques before investigation of its catalytic activity in the synthesis of 1,2,4-triazoloquinazolinones.

FTIR spectra of Melamine@TMG organocatalyst (1). In the FTIR spectrum of melamine (Fig. 1a, A), the bands at 3483 and $3411 \mathrm{~cm}^{-1}$ are related to the asymmetric and symmetric stretching vibrations of the $\mathrm{N}-\mathrm{H}$ bonds of melamine $e^{42,80}$. The band at $1673 \mathrm{~cm}^{-1}$ is attributed to the bending vibrations of the $\mathrm{NH}_{2}$ and the band 
(a)

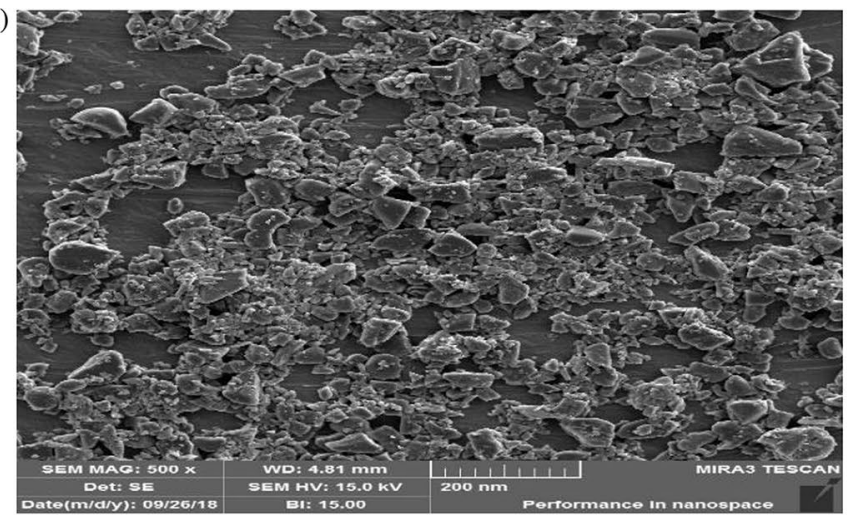

(b)

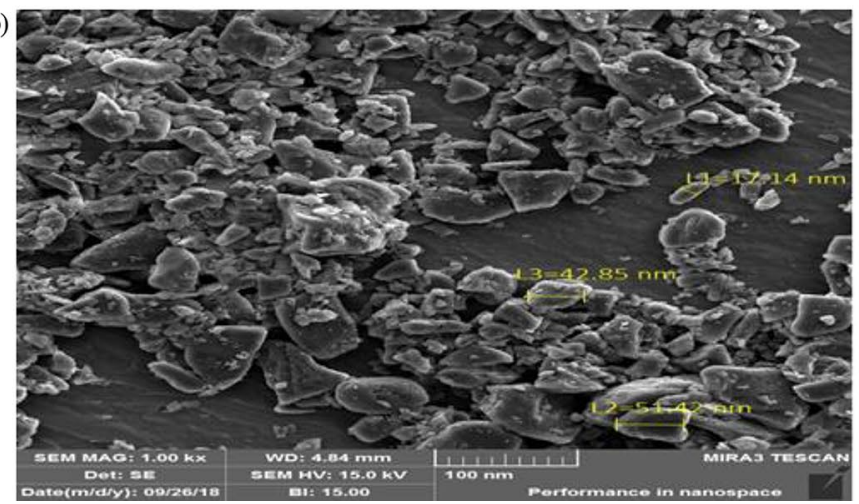

(c)

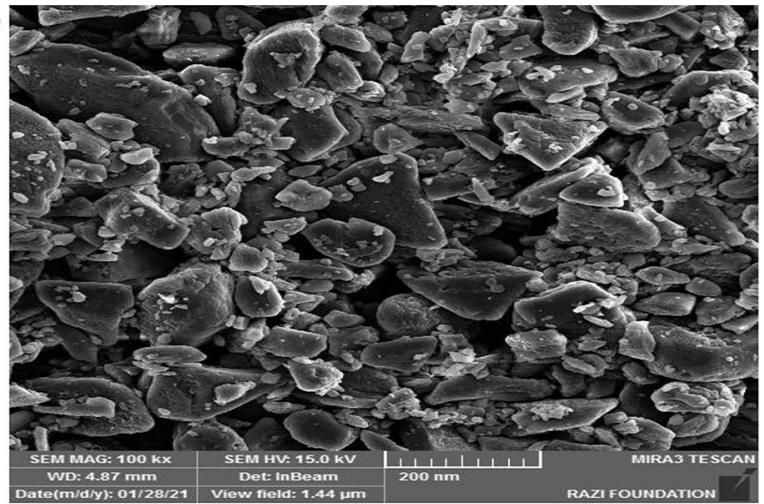

(d)

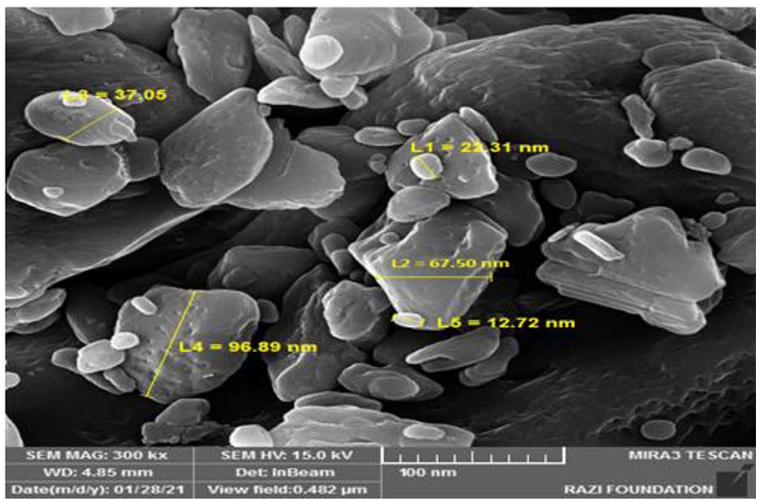

Figure 4. SEM images of the fresh nano-ordered Melamine@TMG (1, a,b) and the recycled Melamine@TMG catalyst after five consecutive runs in the model reaction $(\mathbf{c}, \mathbf{d})$.

at $1525 \mathrm{~cm}^{-1}$ is related to the stretching vibrations of NCN of melamine ${ }^{42,81}$. For the Melamine@PrBr (Fig. 1a, B) and Melamine@TMG (Fig. 1a, C), new signals appeared at 1644, 1540, and $1014 \mathrm{~cm}^{-1}$, which are associated with the stretching and scissoring vibrations of $\mathrm{C}=\mathrm{N}, \mathrm{N}-\mathrm{H}$, and $\mathrm{C}-\mathrm{N}$ bonds of both TMG and melamine, respectively. Appearance of these characteristic bands confirm the existence of TMG moiety in the structure of the catalyst $1^{79}$. By considering this point that there are similar bands in the structure of melamine and TMG, it is not possible to determine clearly the signals of these two structures by FTIR analysis. Furthermore, the FTIR spectra of Melamine@TMG after five consecutive runs in the model reaction (Fig. 1b) demonstrated very good similarity with the fresh catalyst 1. This finding shows that the structure of Melamine@TMG organocatalyst (1) does not change during five consecutive runs.

XRD patterns of the Melamine@TMG organocatalyst (1). Comparative XRD patterns of the Melamine@TMG organocatalyst (1) and its components are presented in Fig. 2. As data in Fig. 2a show, XRD pattern of the melamine has a non-amorphous and crystalline phase $(2 \theta: 13.22,17.78,21.74,22.14,26.28,26.51,28.90,29.89$ and $35.91^{\circ}$ ). Furthermore, the XRD patterns of both Melamine@prBr (Fig. 2b, 20: 13.20, 17.77, 21.73, 22.13, 26.25, 28.89 and $29.88^{\circ}$ ) and Melamine@TMG organocatalyst (1, Fig. 2c, 20:17.74, 21.70, 22.12, 26.24, 28.88, and $29.86^{\circ}$ ) show almost the same peaks compared to the melamine. Although the non-amorphous structure of the melamine has not been completely changed, but the intensity of different peaks has been altered ${ }^{80}$.

Energy dispersive X-ray spectroscopy of the nano-ordered Melamine@TMG (1). The chemical composition of the Melamine@PrBr (I) and Melamine@TMG organocatalyst (1) was determined by energy-dispersive X-ray (EDX) spectroscopy (Fig. 3). The EDX spectra of the Melamine@PrBr and nano-ordered Melamine@TMG showed the expected elements including $\mathrm{Br}, \mathrm{N}$ and $\mathrm{C}$. The obtained results confirm successful anchoring of 1,3-dibromopropane, as the linker, and TMG, as an organic base, to the melamine during depicted steps for preparation of the Melamine@TMG catalyst (1) in Scheme 1.

Scanning electron microscopy images of the Melamine@TMG organocatalyst (1). The scanning electron microscopy (SEM) images demonstrated that the nano-ordered Melamine@TMG (Fig. 4a,b) has a layered structure and the size of nanoparticles are mainly between 17 and $52 \mathrm{~nm}$. On the other hand, the morphology of Melamine@TMG catalyst after five cycles in the model reaction was also preserved considerably (Fig. 4c,d).

Thermal gravimetric analysis and derivative thermogravimetry of the Melamine@TMG (1). The thermogravimetric analysis (TGA) of the Melamine@TMG organocatalyst (1) shows a two-step mass loss of the organic materials between $250-700{ }^{\circ} \mathrm{C}$ (Fig. 5a). The analysis represents that two distinct weight loss stages occur during the pyrolysis of the nanocatalyst. According to data presented in Fig. 5a, the residual mass percent of the 
(a)

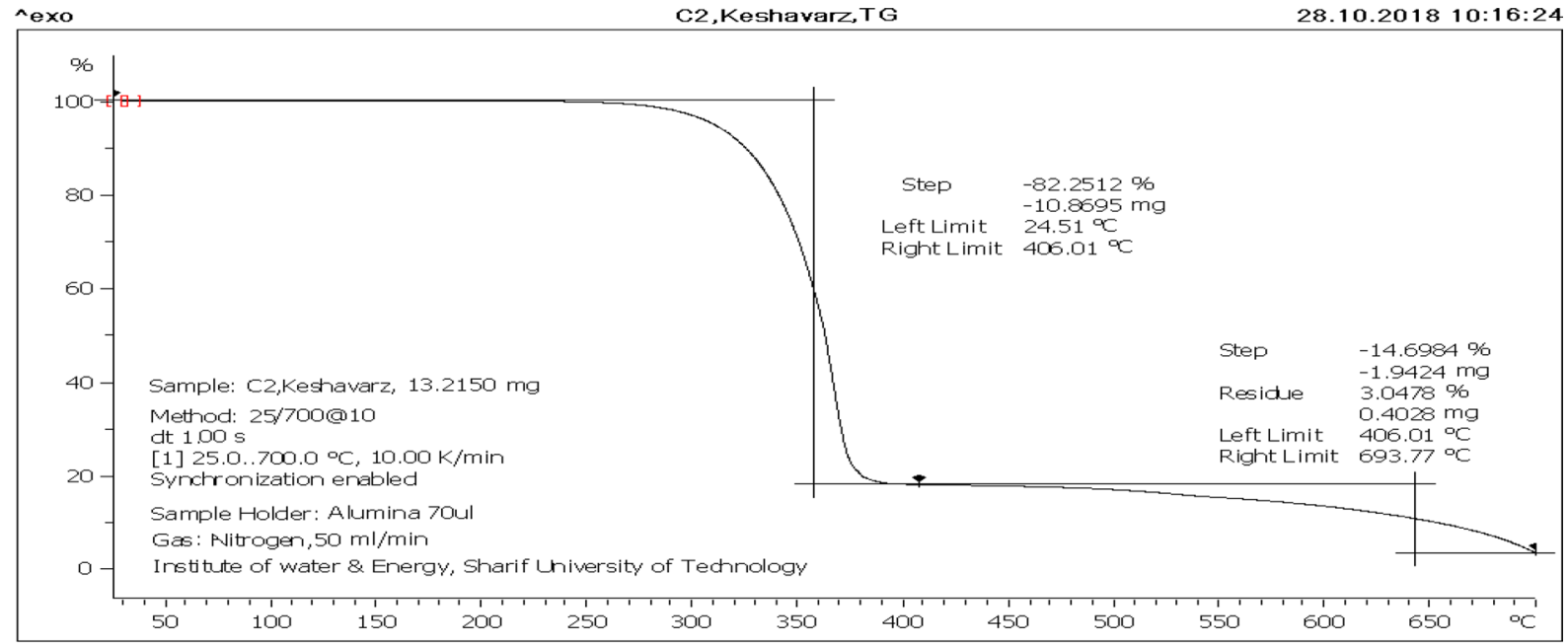

Lab: METTLER

(b)

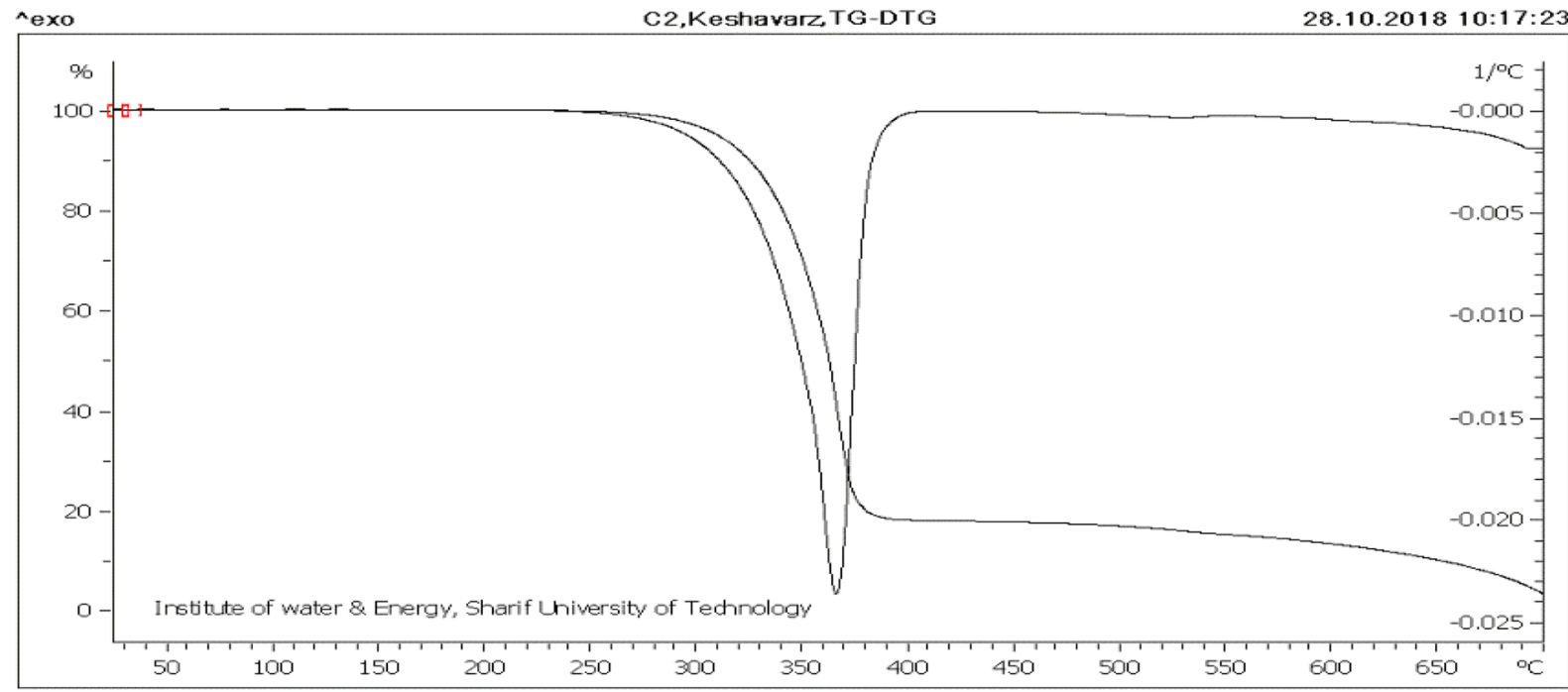

Lab: METTLER

Figure 5. TGA (a) and TG-DTG curves of the Melamine@TMG organocatalyst (1, b).

Melamine@TMG at $700{ }^{\circ} \mathrm{C}$ is about 3.0\%. Therefore, the weight loss of $82 \%$ from 250 to $406^{\circ} \mathrm{C}$ can be attributed mostly to the loss and decomposition of organic TMG, its propylene linkage, and melamine's condensation on heating with the elimination of ammonia to form "melam", "melem", "melon"82, while the second weight loss peaks of $14.69 \%$ in the range of $406-694^{\circ} \mathrm{C}$ can be assigned to complete decomposition of the melamine residue. These findings are also confirmed by the values reported in the derivative thermogravimetry (DTG) analysis (Fig. 5b). The most weight loss occurs at about $370{ }^{\circ} \mathrm{C}$, which is related to the first stage of thermal decomposition. Although this catalyst decomposes mostly at $370{ }^{\circ} \mathrm{C}$, it can be noted that the Melamine@TMG catalyst (1) demonstrated thermal stability up to $250^{\circ} \mathrm{C}$. Hence, it can easily be used in the range of room temperature to $250^{\circ} \mathrm{C}$ without any significant change in its structure and catalytic activity.

Exploration of the catalytic activity of nano-ordered Melamine@TMG organocatalyst (1). The catalytic activity of the as-prepared nano-ordered Melamine@TMG (1) was investigated for the three-component synthesis of 1,2,4-triazoloquinazolinones (Scheme 1). Initially, the three-component reaction of benzaldehyde (4a), 3-amino-1,2,4-triazole (3), and dimedone (2) was carried out in various solvents and the absence/presence of different catalysts to find the optimized conditions for the model reaction. The obtained results are reported in Table 1 . The results revealed that the model reaction in the absence of any catalyst or ordinary acidic and basic catalysts including $\mathrm{CH}_{3} \mathrm{CO}_{2} \mathrm{H}$ and $\mathrm{NaOH}$ proceeds to provide the desired product, 6,6-dimethyl-9-phenyl-5,6,7,9-tetrahydro- $[1,2,4]$ triazolo $[5,1-b]$ quinazolin-8(4H)-one (5a) in longer reaction times and lower yields (Entries 1-5). Indeed, the best results were obtained by using the novel Melamine@TMG nanocatalyst (1) in $\mathrm{EtOH}$, as a green solvent, at $40{ }^{\circ} \mathrm{C}$ (Entries 6-9). The amount of the nanocatalyst loading was also screened (Entries 6-12). It is obvious from the obtained results that by employing $2.5 \mathrm{~mol} \%$ (15 mg) 


\begin{tabular}{|l|l|l|l|l|l|}
\hline Entry & Catalyst (mol\%) & Solvent & Temp. $\left({ }^{\circ} \mathbf{C}\right)$ & Time $(\mathbf{m i n})$ & Yield (\%) \\
\hline 1 & - & EtOH & Reflux & 120 & 45 \\
\hline 2 & - & $\mathrm{H}_{2} \mathrm{O}$ & Reflux & 120 & 34 \\
\hline 3 & - & $\mathrm{CH}_{3} \mathrm{CN}$ & Reflux & 120 & 42 \\
\hline 4 & $\mathrm{CH}_{3} \mathrm{CO}_{2} \mathrm{H}$ & $\mathrm{CH}_{3} \mathrm{CO}_{2} \mathrm{H}$ & 60 & 30 & 76 \\
\hline 5 & NaOH $(1 \mathrm{mmol})$ & $\mathrm{EtOH}$ & Reflux & 30 & 71 \\
\hline 6 & Melamine-TMG $(15 \mathrm{~mol} \%)$ & $\mathrm{EtOH}$ & 40 & 20 & 83 \\
\hline 7 & Melamine-TMG $(5 \mathrm{~mol} \%)$ & $\mathrm{EtOH}$ & 40 & 20 & 88 \\
\hline 8 & Melamine-TMG $(2.5 \mathrm{~mol} \%)$ & EtOH & 40 & 10 & 98 \\
\hline 9 & Melamine-TMG $(2.5 \mathrm{~mol} \%)$ & $\mathrm{EtOH}$ & r.t & 25 & 92 \\
\hline 10 & Melamine-TMG $(2.5 \mathrm{~mol} \%)$ & $\mathrm{EtOH}$ & Reflux & 5 & 99 \\
\hline 11 & Melamine-TMG $(2.5 \mathrm{~mol} \%)$ & $\mathrm{H}_{2} \mathrm{O}$ & 40 & 25 & 87 \\
\hline 12 & Melamine-TMG $(2.5 \mathrm{~mol} \%)$ & $\mathrm{H}_{2} \mathrm{O}$ & Reflux & 15 & 90 \\
\hline
\end{tabular}

Table 1. Optimization of the conditions for the model reaction.

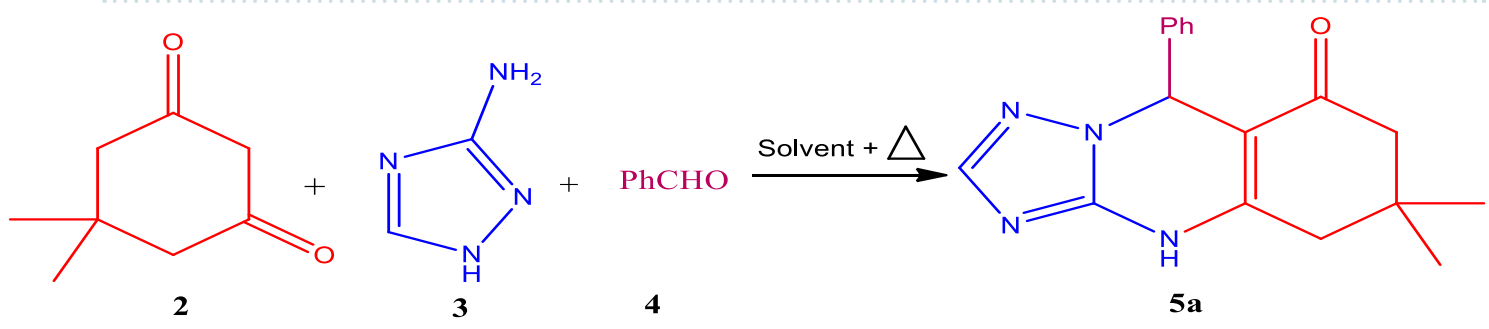

Reaction conditions: dimedone (2,1 mmol), 3-amino-1,2,4-triazole (3,1 mmol), benzaldehyde (4a, $1 \mathrm{mmol})$, catalyst (if not otherwise specified) and solvent $(2 \mathrm{~mL})$.

\begin{tabular}{|c|c|c|c|c|c|c|c|}
\hline \multirow[b]{2}{*}{ Entry } & \multirow[b]{2}{*}{ Aldehyde 4} & \multirow[b]{2}{*}{ Product 5} & \multirow[b]{2}{*}{ Time (min) } & \multirow[b]{2}{*}{ Yield $^{\mathrm{a}}(\%)$} & \multicolumn{3}{|l|}{$\mathrm{Mp}\left({ }^{\circ} \mathrm{C}\right)$} \\
\hline & & & & & Found & Reported & References \\
\hline 1 & $\mathrm{PhCHO}$ & $5 a$ & 10 & 98 & $250-252$ & $248-250$ & $74,77,78$ \\
\hline 2 & $2-\mathrm{MeOC}_{6} \mathrm{H}_{4} \mathrm{CHO}$ & $5 \mathbf{b}$ & 20 & 90 & $242-244$ & $240-243$ & 76,83 \\
\hline 3 & $3,4-(\mathrm{MeO})_{2} \mathrm{C}_{6} \mathrm{H}_{3} \mathrm{CHO}$ & $5 c$ & 25 & 89 & $225-227$ & - & This work \\
\hline 4 & $4-\mathrm{MeC}_{6} \mathrm{H}_{4} \mathrm{CHO}$ & $5 d$ & 20 & 86 & $262-264$ & $264-269$ & 74,78 \\
\hline 5 & $4-\mathrm{ClC}_{6} \mathrm{H}_{4} \mathrm{CHO}$ & $5 e$ & 8 & 98 & $303-305$ & $303-305$ & 74,78 \\
\hline 6 & $3-\mathrm{O}_{2} \mathrm{NC}_{6} \mathrm{H}_{4} \mathrm{CHO}$ & $5 f$. & 5 & 97 & $267-269$ & $266-269$ & 74,78 \\
\hline 7 & $4-\mathrm{O}_{2} \mathrm{NC}_{6} \mathrm{H}_{4} \mathrm{CHO}$ & $5 \mathrm{~g}$ & 5 & 98 & $294-297$ & $290-294$ & 84 \\
\hline 8 & $4-\mathrm{HOC}_{6} \mathrm{H}_{4} \mathrm{CHO}$ & $5 \mathrm{~h}$ & 20 & 91 & $305-308$ & $>300$ & 74,78 \\
\hline 9 & $3,4-(\mathrm{Cl})_{2} \mathrm{C}_{6} \mathrm{H}_{3} \mathrm{CHO}$ & $5 \mathbf{i}$ & 5 & 99 & $324-326$ & - & This work \\
\hline 10 & $4-\mathrm{FC}_{6} \mathrm{H}_{4} \mathrm{CHO}$ & $5 \mathbf{j}$ & 5 & 99 & $257-259$ & $258-260$ & 85 \\
\hline
\end{tabular}

Table 2. Synthesis of various derivatives of 1,2,4-triazoloquinazolinones $\mathbf{5 a - j}$ catalyzed by the nano-ordered Melamine@TMG organocatalyst (1).<smiles>CC1(C)CC(=O)CC(=O)C1</smiles>

2<smiles>Nc1nc[nH]n1</smiles>

3
$\mathrm{ArCHO}$

Melamine@TMG $\mathrm{EtOH} / 40^{\circ} \mathrm{C}$

4a-j<smiles>CC1(C)CC(=O)C2=C(C1)Nc1ncnn1C2Br</smiles>

Reaction conditions: dimedone (2,1 mmol), 3-amino-1,2,4-triazole (3,1 mmol), aldehyde (4a-j, $1 \mathrm{mmol})$, Melamine@TMG nanocatalyst $(1,2.5 \mathrm{~mol} \%, 15 \mathrm{mg})$ in EtOH $(2 \mathrm{~mL})$ at $40{ }^{\circ} \mathrm{C} .{ }^{\mathrm{b}}$ Isolated yield. 

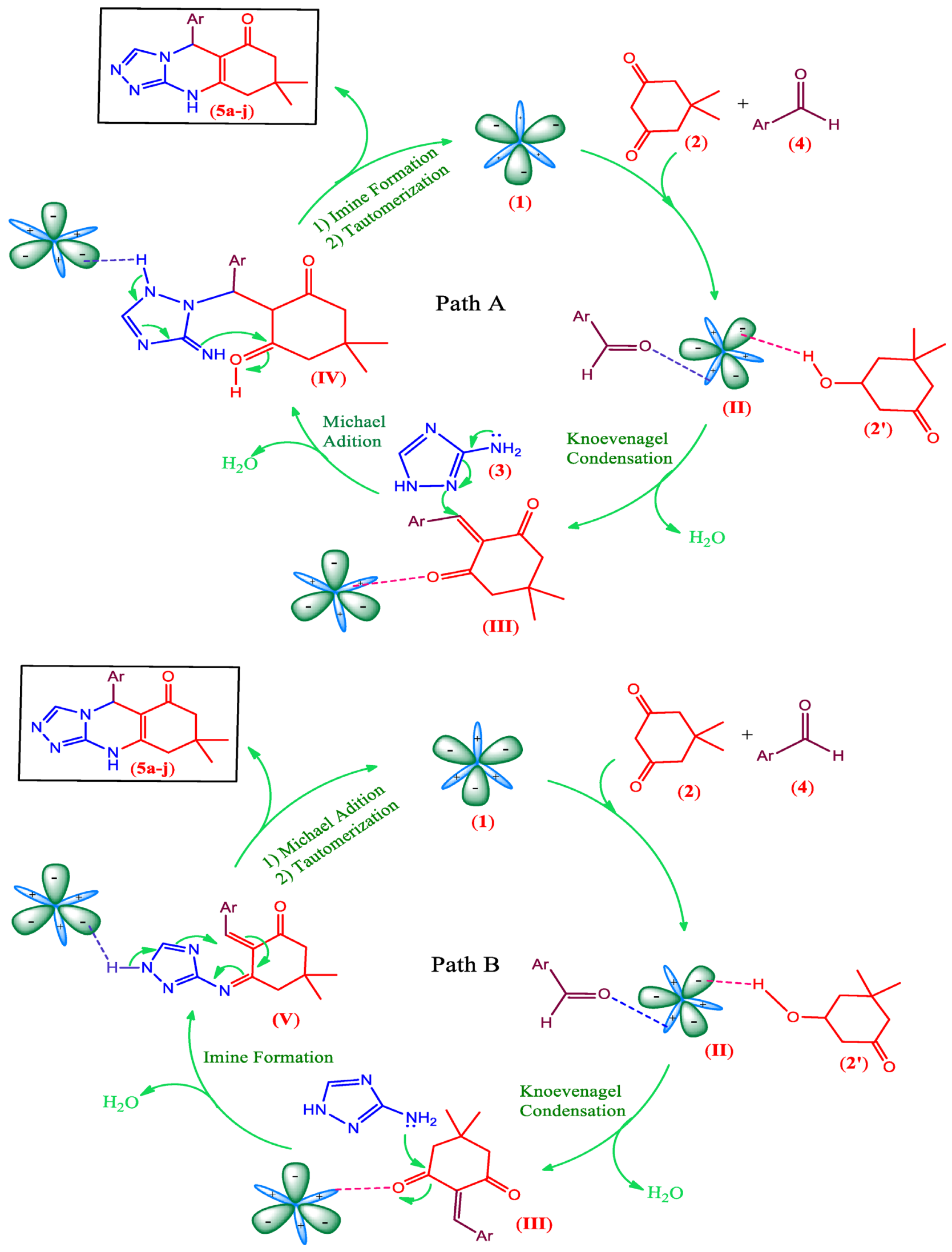

Scheme 2. Proposed mechanism for the synthesis of 1,2,4-triazoloquinazolinones $\mathbf{5 a}-\mathbf{j}$ catalyzed by the nanoordered Melamine@TMG organocatalyst (1). 


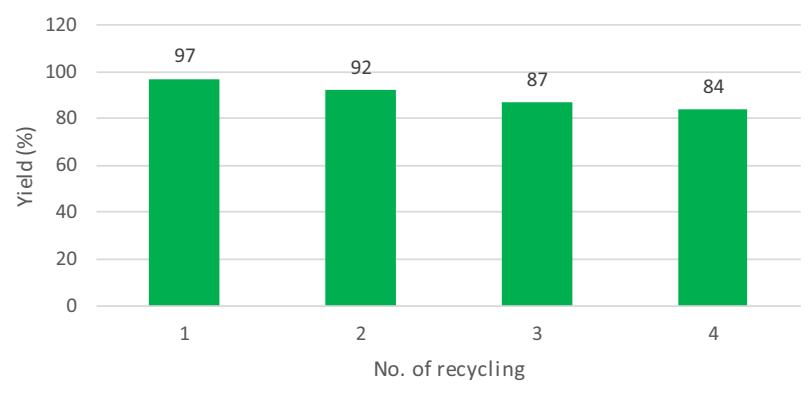

Figure 6. Recycling chart for the Melamine@TMG nanocatalyst $\mathbf{1}$ in the synthesis of $\mathbf{5 a}$.

\begin{tabular}{|l|l|l|l|l|l|}
\hline Entry & Catalyst $($ loading/solvent $)$ & Temperature $\left({ }^{\circ} \mathrm{C}\right)$ & Time $(\mathbf{m i n})$ & Yield $(\%)$ & References \\
\hline 1 & Melamine@TMG $(2.5 \mathrm{~mol} \% / \mathrm{EtOH})$ & 40 & 10 & 98 & This work \\
\hline 2 & Nano-SiO $2\left(15 \mathrm{~mol} \% / \mathrm{CH}_{3} \mathrm{CN}\right)$ & r.t & 30 & 96 & 71 \\
\hline 3 & $p$-Toluenesulfonic acid $\left(15 \mathrm{~mol} \% / \mathrm{CH}_{3} \mathrm{CN}\right)$ & 50 & 25 & 95 & 73 \\
\hline 4 & {$\left[\mathrm{Bmim}_{\mathrm{BF}}(15 \mathrm{~mol} \% /\right.$ Solvent-Free $)$} & r.t & 11 & 92 & 77 \\
\hline 5 & {$\left[\mathrm{C}_{4}(\mathrm{H}-\mathrm{DABCO})_{2}\right]\left[\mathrm{HSO}_{4}\right]_{4}(16 \mathrm{mg} /$ Solvent-Free $)$} & 90 & 12 & 91 & 67 \\
\hline 6 & Molecular iodine $\left(10 \mathrm{~mol} \% / \mathrm{CH}_{3} \mathrm{CN}\right)$ & Reflux & 10 & 81 & 76 \\
\hline 7 & Anthranilic acid $(30 \mathrm{~mol} \% / \mathrm{EtOH})$ & 80 & 10 & 95 & 75 \\
\hline
\end{tabular}

Table 3. Comparison of the catalytic activity of nano-ordered Melamine@TMG organocatalyst (1) versus some introduced catalysts for the synthesis of $\mathbf{5 a}$.

nanocatalyst loading in $\mathrm{EtOH}$ at $40{ }^{\circ} \mathrm{C}$, the reaction affords the desired 1,2,4-triazoloquinazolinone 5a in lower reaction time and excellent yield $(>98 \%$, Entry 8$)$.

In the next step, other carbocyclic aromatic aldehydes $\mathbf{5 b}-\mathbf{j}$ with different substituents were used to develop the scope of the studied three-component reaction catalyzed by the multifunctional Melamine@TMG organocatalyst (1). The obtained results have been summarized in Table 2. As data in Table 2 show, all the studied aldehydes with both electron-withdrawing and electron-donating substituents were involved in the optimized conditions smoothly to produce the corresponding products in high to excellent yields. In general, the kind and position of functional groups on the aromatic ring of aldehyde exhibits an obvious impact on the required time for completion of the reaction. Indeed, aromatic aldehydes bearing electron-donating substituents (Entries 2-4 and 8) required longer reaction times compared to those ones containing electron-withdrawing groups (Entries 5-7 and 9,10).

According to the functional groups existing in the structure of catalyst $\mathbf{1}$ and reactivity of different aldehydes $\mathbf{4 a}-\mathbf{j}$, a reasonable mechanism for the synthesis of 1,2,4-tria-zoloquinazolinones $\mathbf{5 a - j}$ catalyzed by the multifunctional Melamine@TMG organocatalyst (1) is presented in Scheme 2. In the presence of the melamine-TMG nanocatalyst, the dimedone component 2 equilibrates with its corresponding enol form $\mathbf{2}^{\prime}$ and reacts with the activated aldehydes 4 to form the intermediate III through the Knoevenagel condensation. After formation of the intermediate III, there are two possible paths for the reaction: Intermediate III at first takes part in the Michael addition with 3-amino-1,2,4-triazole 3 to form the intermediate IV and subsequent cyclization by imine formation. Then, the desired products $\mathbf{5} \mathbf{a}-\mathbf{j}$ are formed after tautomerization of the obtained cyclic imine to its corresponding enamine as the last step (Path A). Simultaneously, one of the carbonyl groups in the intermediate III can be activated by the catalyst $\mathbf{1}$ to form the corresponding imine (intermediate $\mathbf{V}$ ). Then, heteroannaulation occurs by the intramolecular Michael addition to afford the desired 1,2,4-triazoloquinazolinones $\mathbf{5 a - j}(\text { Path B })^{11,13,33,86-90}$. It should be noted that the only byproducts of the reaction are water molecules with no environmental impact and can be dissolved in $\mathrm{EtOH}$, as a green solvent, to promote the reaction efficiently by the nano-ordered Melamine@TMG organocatalyst (1).

As a part of our study, the recyclability of Melamine@TMG organocatalyst (1) was also examined in the synthesis of model compound $\mathbf{5 a}$. The results are reported in Fig. 6 . Indeed, it was observed that the catalytic activity of catalyst $\mathbf{1}$ changed a little after four consecutive runs using the recycled samples .

To show the merits of the nano-ordered Melamine@TMG organocatalyst (1) for the multicomponent synthesis of 1,2,4-triazoloquinazolinones in comparison to the previously reported catalytic systems, Table 3 compares the obtained results for the synthesis of model compound 5a. It is obvious that the excellent yield of 1,2,4-triazoloquinazolinone 5a was achieved using a low loading of the present catalyst in a green solvent or at a lower temperature compared to the other reported systems. 


\section{Conclusion}

In general, the novel nano-ordered 1,1,3,3-tetramethylguanidine-functionalized melamine (Melamine@TMG) organocatalyst was prepared and adequately characterized by various spectroscopic or microscopic methods as well as analytical techniques. The basic property of the catalyst was significantly increased by the incorporation of 1,1,3,3-tetramethylguanidine moiety while melamine itself acts as a bifunctional organocatalyst. The nanoordered multifunctional Melamine@TMG organocatalyst was successfully used, as an efficient recyclable catalyst, for the three-component synthesis of 1,2,4-triazoloquinazolinone scaffold from 3-amino-1,2,4-triazole, dimedone, and different aryl aldehydes under green and environmentally-benign conditions. This practical method afforded the corresponding products in high to excellent yields within short reaction times. Using a heterogeneous multifunctional nanocatalyst, simple work-up procedure with no need for chromatographic purification, affording highly selective conversion, and recyclability of the catalyst with only a small decrease in its activity are other main advantages of this new practical protocol for the synthesis of 1,2,4-triazoloquinazolinones.

Received: 13 November 2020; Accepted: 27 May 2021

Published online: 14 July 2021

\section{References}

1. List, B. Introduction: Organocatalysis. Chem. Rev. 107, 5413-5415. https://doi.org/10.1021/cr078412e (2007).

2. van der Helm, M. P., Klemm, B. \& Eelkema, R. Organocatalysis in aqueous media. Nat. Rev. Chem. 3, 491-508. https://doi.org/10. 1038/s41570-019-0116-0 (2019).

3. Zhang, Z. et al. Asymmetric counteranion-directed Lewis acid organocatalysis for the scalable cyanosilylation of aldehydes. Nat. Commun. 7, 12478. https://doi.org/10.1038/ncomms12478 (2016).

4. Wende, R. C. \& Schreiner, P. R. Evolution of asymmetric organocatalysis: Multi- and retrocatalysis. Green Chem. 14, $1821-1849$. https://doi.org/10.1039/C2GC35160A (2012).

5. Volla, C. M. R., Atodiresei, I. \& Rueping, M. Catalytic C-C bond-forming multi-component cascade or domino reactions: Pushing the boundaries of complexity in asymmetric organocatalysis. Chem. Rev. 114, 2390-2431. https://doi.org/10.1021/cr400215u (2014).

6. Renzi, P. \& Bella, M. Non-asymmetric organocatalysis. Chem. Commun. 48, 6881-6896. https://doi.org/10.1039/C2CC31599H (2012).

7. De Risi, C. et al. Recent advances in continuous-flow organocatalysis for process intensification. React. Chem. Eng. 5, 1017-1052. https://doi.org/10.1039/D0RE00076K (2020).

8. Chakraborty Ghosal, N. et al. Organocatalysis by an aprotic imidazolium zwitterion: Regioselective ring-opening of aziridines and applicable to gram scale synthesis. Green Chem. 18, 565-574. https://doi.org/10.1039/C5GC01323B (2016).

9. Liu, D. \& Chen, E. Y. X. Organocatalysis in biorefining for biomass conversion and upgrading. Green Chem. 16, 964-981. https:// doi.org/10.1039/C3GC41934G (2014).

10. Cokoja, M., Wilhelm, M. E., Anthofer, M. H., Herrmann, W. A. \& Kühn, F. E. Synthesis of cyclic carbonates from epoxides and carbon dioxide by using organocatalysts. Chemsuschem 8, 2436-2454. https://doi.org/10.1002/cssc.201500161 (2015).

11. Dekamin, M. G., Karimi, Z. \& Farahmand, M. Tetraethylammonium 2-(N-hydroxycarbamoyl)benzoate: A powerful bifunctional metal-free catalyst for efficient and rapid cyanosilylation of carbonyl compounds under mild conditions. Catal. Sci. Technol. 2, 1375-1381. https://doi.org/10.1039/C2CY20037F (2012).

12. Dekamin, M. G., Yazdaninia, N., Mokhtari, J. \& Naimi-Jamal, M. R. Tetrabutylammonium phthalimide-N-oxyl: An efficient organocatalyst for trimethylsilylation of alcohols and phenols with hexamethyldisilazane. J. Iran. Chem. Soc. 8, 537-544. https:// doi.org/10.1007/BF03249088 (2011).

13. Dekamin, M. G., Sagheb-Asl, S. \& Reza Naimi-Jamal, M. An expeditious synthesis of cyanohydrin trimethylsilyl ethers using tetraethylammonium 2-(carbamoyl)benzoate as a bifunctional organocatalyst. Tetrahedron Lett. 50, 4063-4066. https://doi.org/ 10.1016/j.tetlet.2009.04.090 (2009)

14. Miller, T. S. et al. Carbon nitrides: Synthesis and characterization of a new class of functional materials. Phys. Chem. Chem. Phys. 19, 15613-15638. https://doi.org/10.1039/C7CP02711G (2017).

15. Benzigar, M. R. et al. Recent advances in functionalized micro and mesoporous carbon materials: Synthesis and applications. Chem. Soc. Rev. 47, 2680-2721. https://doi.org/10.1039/C7CS00787F (2018).

16. Ghosh, A. et al. A green approach for the preparation of a surfactant embedded sulfonated carbon catalyst towards glycerol acetalization reactions. Catal. Sci. Technol. 10, 4827-4844. https://doi.org/10.1039/D0CY00336K (2020).

17. Shen, Y., Ge, X. \& Chen, M. Catalytic oxidation of nitric oxide (NO) with carbonaceous materials. RSC Adv. 6, 8469-8482. https:// doi.org/10.1039/C5RA24148K (2016).

18. Shen, W. \& Fan, W. Nitrogen-containing porous carbons: Synthesis and application. J. Mater. Chem. A 1, 999-1013. https://doi. org/10.1039/C2TA00028H (2013).

19. Su, Q. et al. Urea-derived graphitic carbon nitride as an efficient heterogeneous catalyst for $\mathrm{CO}_{2}$ conversion into cyclic carbonates. Catal. Sci. Technol. 4, 1556-1562. https://doi.org/10.1039/C3CY00921A (2014).

20. Dupont, J. From molten salts to ionic liquids: A "Nano" journey. Acc. Chem. Res. 44, 1223-1231. https://doi.org/10.1021/ar200 0937 (2011).

21. Moradi, S., Zolfigol, M. A., Zarei, M., Alonso, D. A. \& Khoshnood, A. Synthesis of a biological-based glycoluril with phosphorous acid tags as a new nanostructured catalyst: Application for the synthesis of novel natural henna-based compounds. ChemistrySelect 3, 3042-3047. https://doi.org/10.1002/slct.201702544 (2018).

22. Climent, M. J., Corma, A. \& Iborra, S. Homogeneous and heterogeneous catalysts for multicomponent reactions. RSC Adv. 2, $16-58$ (2012).

23. Chen, Q. et al. Sustainable synthesis of supported metal nanocatalysts for electrochemical hydrogen evolution. Chin. J. Catal. 41, 1791-1811 (2020).

24. Gawande, M. B., Zboril, R., Malgras, V. \& Yamauchi, Y. Integrated nanocatalysts: A unique class of heterogeneous catalysts. J. Mater. Chem. A 3, 8241-8245 (2015).

25. Geetmani Singh, N. et al. Synthetic, mechanistic and kinetic studies on the organo-nano catalyzed synthesis of oxygen and nitrogen containing Spiro compounds under ultrasonic condition. Green Chem. 18, 4216-4227 (2016).

26. Mercuri, F., Baldoni, M. \& Sgamellotti, A. Towards nano-organic chemistry: Perspectives for a bottom-up approach to the synthesis of low-dimensional carbon nanostructures. Nanoscale 4, 369-379 (2012).

27. Safaei-Ghomi, J., Masoomi, R., Hamadanian, M. \& Naseh, S. Magnetic nanoscaled core-shell structured Fe $\mathrm{O}_{4} @ \mathrm{~L}-\mathrm{proline}$ An efficient, reusable and eco-friendly nanocatalyst for diastereoselective synthesis of fulleropyrrolidines. New J. Chem. 40, 3289-3299 (2016) 
28. Farokhian, P., Mamaghani, M., Mahmoodi, N. O. \& Tabatab-aeian, K. A green and practical method for the synthesis of novel pyrano[2,3-c]pyrazoles and bis-pyrano[2,3-c]pyrazoles using sulfonic acid-functionalized ionic liquid. J. Iran Chem. Soc. 15, 11-16 (2018).

29. Jahanshahi, P. \& Mamaghani, M. Efficient and straightforward access to diverse and densely functionalized chromenes by 3-amino-1,2,4-triazole supported on hydroxyapatite-encapsulated- $\gamma-\mathrm{Fe}_{2} \mathrm{O}_{3}\left(\gamma-\mathrm{Fe}_{2} \mathrm{O}_{3} @ \mathrm{HAp} @\right.$ CPTMS@AT) as a new magnetic basic nanocatalyst. React. Kinet. Mech. Catal. 130, 955-977. https://doi.org/10.1007/s11144-020-01825-5 (2020).

30. Mashhadinezhad, M., Shirini, F., Mamaghani, M. \& Rassa, M. Green synthesis of dihydropyrimidine annulated heterocyclic systems catalyzed by nanoporous Na+-montmorillonite perchloric acid and evaluation of their biological activities. Polycycl. Aromat. Compd. 40, 1417-1433. https://doi.org/10.1080/10406638.2018.1553197 (2020).

31. Mardhiah, H. H., ChyuanOng, H., Masjuki, H. H. \& Lim, S. A review on latest developments and future prospects of heterogeneous catalyst in biodiesel production from non-edible oils. Renew. Sust. Energy. Rev. 67, 1225-1236 (2017).

32. Akbari, A., Dekamin, M. G., Yaghoubi, A. \& Naimi-Jamal, M. R. Novel magnetic propylsulfonic acid-anchored isocyanuratebased periodic mesoporous organosilica (Iron oxide@ PMO-ICS-PrSO3H) as a highly efficient and reusable nanoreactor for the sustainable synthesis of imidazopyrimidine derivatives. Sci. Rep. 10, 10646. https://doi.org/10.1038/s41598-020-67592-4 (2020).

33. Karami, S., Dekamin, M. G., Valiey, E. \& Shakib, P. DABA MNPs: A new and efficient magnetic bifunctional nanocatalyst for green synthesis of biologically active pyrano [2, 3-c] pyrazole and benzylpyrazolyl coumarin derivatives. New. J. Chem. 44, 13952-13961. https://doi.org/10.1039/D0NJ02666B (2020).

34. Alexander, J., Benford, D., Cockburn, A. \& Cravedi, J. Polycyclic aromatic hydrocarbons in food1 scientific opinion of the panel on contaminants in the food chain. EFSA J. 724, 1-114 (2008).

35. Liu, Q. \& Mei Ai, H. Ultrasound promoted synthesis of arylmethylenemalonitriles catalyzed by melamine. J. Chem. Soc. Pak. 38, 565-569 (2016).

36. Natu, M. \& Van De Mark, M. R. Synthesis and characterization of an acid catalyst for acrylic-melamine resin systems based on colloidal unimolecular polymer (CUP) particles of MMA-AMPS. Prog. Org. Coat. 81, 35-46 (2015).

37. Savateev, A. \& Antonietti, M. Heterogeneous organocatalysis for photoredox chemistry. ACS Catal. 8, 9790-9808. https://doi.org/ 10.1021/acscatal.8b02595 (2018).

38. Prasetyanto, E. A., Ansari, M. B., Min, B.-H. \& Park, S.-E. Melamine tri-silsesquioxane bridged periodic mesoporous organosilica as an efficient metal-free catalyst for $\mathrm{CO}_{2}$ activation. Catal. Today 158, 252-257. https://doi.org/10.1016/j.cattod.2010.03.081 (2010).

39. Elavarasan, S., Kala, K., Muhammad, I., Bhaumik, A. \& Sasidharan, M. Pd-chelated 1,3,5-triazine organosilica as an active catalyst for Suzuki and Heck reactions. Mol. Catal. 476, 110521. https://doi.org/10.1016/j.mcat.2019.110521 (2019).

40. Muhammad, R. \& Mohanty, P. Nitrogen enriched triazine bridged mesoporous organosilicas for $\mathrm{CO}_{2}$ capture and dye adsorption applications. J. Mol. Liq. 248, 127-134. https://doi.org/10.1016/j.molliq.2017.10.036 (2017).

41. Valiey, E., Dekamin, M. G. \& Alirezvani, Z. Melamine-modified chitosan materials: An efficient and recyclable bifunctional organocatalyst for green synthesis of densely functionalized bioactive dihydropyrano[2,3-c]pyrazole and benzylpyrazolyl coumarin derivatives. Int. J. Biol. Macromol. 129, 407-421. https://doi.org/10.1016/j.ijbiomac.2019.01.027 (2019).

42. Alirezvani, Z., Dekamin, M. G., Davoodi, F. \& Valiey, E. Melamine-functionalized chitosan: A new bio-based reusable bifunctional organocatalyst for the synthesis of cyanocinnamonitrile intermediates and densely functionalized nicotinonitrile derivatives. ChemistrySelect 3, 10450-10463. https://doi.org/10.1002/slct.201802010 (2018).

43. Alirezvani, Z., Dekamin, M. G. \& Valiey, E. Cu(II) and magnetite nanoparticles decorated melamine-functionalized chitosan: A synergistic multifunctional catalyst for sustainable cascade oxidation of benzyl alcohols/Knoevenagel condensation. Sci. Rep. 9, 17758. https://doi.org/10.1038/s41598-019-53765-3 (2019).

44. Taylor, J. E., Bull, S. D. \& Williams, J. M. J. Amidines, isothioureas, and guanidines as nucleophilic catalysts. Chem. Soc. Rev. 41, 2109-2121. https://doi.org/10.1039/C2CS15288F (2012).

45. Wang, Z., Gérardy, R., Gauron, G., Damblon, C. \& Monbaliu, J.-C.M. Solvent-free organocatalytic preparation of cyclic organic carbonates under scalable continuous flow conditions. React. Chem. Eng. 4, 17-26. https://doi.org/10.1039/C8RE00209F (2019).

46. Ahmad, S. M., Braddock, D. C., Cansell, G. \& Hermitage, S. A. Dimethylformamide, dimethylacetamide and tetramethylguanidine as nucleophilic organocatalysts for the transfer of electrophilic bromine from $\mathrm{N}$-bromosuccinimide to alkenes. Tetrahedron Lett. 48, 915-918. https://doi.org/10.1016/j.tetlet.2006.12.042 (2007).

47. Dong, S., Feng, X. \& Liu, X. Chiral guanidines and their derivatives in asymmetric synthesis. Chem. Soc. Rev. 47, 8525-8540. https://doi.org/10.1039/C7CS00792B (2018).

48. Selig, P. Guanidine organocatalysis. Synthesis 45, 703-718. https://doi.org/10.1055/s-0032-1318154 (2013).

49. Lohmeijer, B. G. G. et al. Guanidine and amidine organocatalysts for ring-opening polymerization of cyclic esters. Macromolecules 39, 8574-8583. https://doi.org/10.1021/ma0619381 (2006).

50. Odagi, M., Takayama, K., Sato, M., Yamanaka, M. \& Nagasawa, K. Development of guanidine-bisurea bifunctional organocatalysts with a chiral pyrrolidine moiety and application to $\alpha$-hydroxylation of tetralone-derived $\beta$-Keto esters. Molecules 20, 12590-12598 (2015).

51. Patel, D. M., Vala, R. M., Sharma, M. G., Rajani, D. P. \& Patel, H. M. A Practical green visit to the functionalized $[1,2,4]$ Triazolo[5,1b] quinazolin- $8(4 \mathrm{H})$ one scaffolds using the group-assisted purification (GAP) chemistry and their pharmacological testing. ChemistrySelect 4, 1031-1041. https://doi.org/10.1002/slct.201803605 (2019).

52. Patel, C. et al. Synthesis and antimicrobial activity of 1,2-benzothiazine derivatives. Molecules 21, 861 (2016).

53. Glasser, A. C., Diamond, L. \& Combs, G. Synthesis and anticonvulsant activity of substituted 2-thioquinazolin-4-ones I: Preliminary studies. J. Pharm. Sci. 60, 127-129 (1971).

54. Alagarsamy, V., Solomon, V. R. \& Murugan, M. Synthesis and pharmacological investigation of novel 4-benzyl-1-substituted$4 \mathrm{H}-[1,2,4]$ triazolo[4,3-a]quinazolin-5-ones as new class of H1-antihistaminic agents. Bioorg. Med. Chem. 15, 4009-4015 (2007).

55. Pathak, S. R., Malhotra, V., Nath, R. \& Shanker, K. Synthesis and antihypertensive activity of novel quinazolin-4(3H)-one derivatives. Cent Nerv. Syst. Agents Med. Chem. 14, 34-38 (2014).

56. Zarganes-Tzitzikas, T., Chandgude, A. L. \& Dömling, A. Multicomponent reactions, union of MCRs and beyond. Chem. Rec. 15, 981-996. https://doi.org/10.1002/tcr.201500201 (2015).

57. Prasad, P., Shobhashana, P. G. \& Patel, M. P. An efficient synthesis of $4 \mathrm{H}$-pyrano quinolinone derivatives catalysed by a versatile organocatalyst tetra- $n$-butylammonium fluoride and their pharmacological screening. R. Soc. Open Sci. 4, 170764 (2017).

58. Eckert, H. Diversity oriented syntheses of conventional heterocycles by smart multi component reactions (MCRs) of the last decade. Molecules 17, 1074-1102 (2012).

59. Slobbe, P., Ruijter, E. \& Orru, R. V. A. Recent applications of multicomponent reactions in medicinal chemistry. MedChem Comm 3, 1189-1218. https://doi.org/10.1039/C2MD20089A (2012).

60. Zhi, S., Ma, X. \& Zhang, W. Consecutive multicomponent reactions for the synthesis of complex molecules. Org. Biomol. Chem. 17, 7632-7650. https://doi.org/10.1039/С9ОВ00772E (2019).

61. Zadmard, R., Akbarzadeh, A. \& Jalali, M. R. Highly functionalized calix[4]arenes via multicomponent reactions: Synthesis and recognition properties. RSC Adv. 9, 19596-19605. https://doi.org/10.1039/C9RA03354H (2019).

62. Dekamin, M. G., Azimoshan, M. \& Ramezani, L. Chitosan: A highly efficient renewable and recoverable bio-polymer catalyst for the expeditious synthesis of $\alpha$-amino nitriles and imines under mild conditions. Green Chem. 15, 811-820. https://doi.org/10. 1039/C3GC36901C (2013). 
63. Etivand, N., Khalafy, J. \& Dekamin, M. G. Fast and efficient green procedure for the synthesis of Benzo[5,6]chromene derivatives and their sulfur analogues in water by organocatalyst potassium phthalimide- $N$-oxyl. Synthesis 52, 1707-1718. https://doi.org/10. 1055/s-0037-1610755 (2020).

64. Dekamin, M. G., Eslami, M. \& Maleki, A. Potassium phthalimide-N-oxyl: A novel, efficient, and simple organocatalyst for the one-pot three-component synthesis of various 2 -amino- $4 \mathrm{H}$-chromene derivatives in water. Tetrahedron $69,1074-1085$. https:// doi.org/10.1016/j.tet.2012.11.068 (2013).

65. Zolfigol, M. A. et al. 4-Phenyl-1,2,4-triazole-3,5-dione as a novel and reusable reagent for the aromatization of 1,4-dihydropyridines under mild conditions. Tetrahedron Lett. 46, 5581-5584. https://doi.org/10.1016/j.tetlet.2005.06.031 (2005).

66. Zolfigol, M. A. et al. Synthesis of 1,2,3-triazolylmethoxyphenyl[1,2,4]triazolo[1,2-a]indazoletrione derivatives by combining click and multicomponent reactions. Synthesis 48, 1518-1524. https://doi.org/10.1055/s-0035-1561392 (2016).

67. Safari, N., Shirini, F. \& Tajik, H. Preparation and characterization of a novel DABCO based tetra cationic ionic liquid as a reusable catalyst for the multi-component synthesis of $2 \mathrm{H}$-indazolo[2,1-b]phthalazine-trione and $[1,2,4]$ triazoloquinazolinone derivatives under solvent-free condition. J. Mol. Struct. 1201, 127143. https://doi.org/10.1016/j.molstruc.2019.127143 (2020).

68. Bakhshali-Dehkordi, R., Ghasemzadeh, M. A. \& Safaei-Ghomi, J. Multicomponent preparation of quinazolinone derivatives in the presence of $\mathrm{TiO}_{2}$ nanoparticles supported ionic liquids. Polycycl. Aromat. Compd. https://doi.org/10.1080/10406638.2020.17596 $61(2020)$.

69. Karimi-Chayjani, R., Daneshvar, N., Nikoo Langarudi, M. S., Shirini, F. \& Tajik, H. Silica-coated magnetic nanoparticles containing bis dicationic bridge for the synthesis of 1,2,4-triazolo pyrimidine/quinazolinone derivatives. J. Mol. Struct. 1199, 126891. https:// doi.org/10.1016/j.molstruc.2019.126891 (2020).

70. Mohammadi Ziarani, G., Badiei, A., Aslani, Z. \& Lashgari, N. Application of sulfonic acid functionalized nanoporous silica (SBA$\mathrm{Pr}-\mathrm{SO} 3 \mathrm{H}$ ) in the green one-pot synthesis of triazoloquinazolinones and benzimidazoquinazolinones. Arab. J. Chem. 8, 54-61. https://doi.org/10.1016/j.arabjc.2011.06.020 (2015).

71. Mousavi, M. R. \& Maghsoodlou, M. T. Nano-SiO 2 : A green, efficient, and reusable heterogeneous catalyst for the synthesis of quinazolinone derivatives. J. Iran. Chem. Soc. 12, 743-749 (2015).

72. Ayati, A., Daraie, M., Heravi, M. M. \& Tanhaei, B. $\mathrm{H}_{4}\left[\mathrm{~W}_{12} \mathrm{SiO}_{40}\right]$ grafted on magnetic chitosan: A green nanocatalyst for the synthesis of $[1,2,4]$ triazolo/benzimidazolo quinazolinone derivatives. Micro Nano Lett. 12, 964-969. https://doi.org/10.1049/mnl. 2017.0053 (2017).

73. Mousavi, M. R. \& Maghsoodlou, M. T. Catalytic systems containing p-toluenesulfonic acid monohydrate catalyzed the synthesis of triazoloquinazolinone and benzimidazoquinazolinone derivatives. Monatshefte Chem. 145, 1967-1973 (2014).

74. Heravi, M. M., Derikvand, F. \& Ranjbar, L. Sulfamic acid-catalyzed, three- component, one-pot synthesis of $[1,2,4]$ triazolo/benzimidazolo quinazolinone derivatives. Synth. Commun. 40, 677-685 (2010).

75. Vibhute, S. et al. An efficient, one-pot three components synthesis of $[1,2,4]$ triazoloquinazolinone derivatives using anthranilic acid as green catalyst. Res. Chem. Intermed. 43, 4561-4574. https://doi.org/10.1007/s11164-017-2896-5 (2017).

76. Goud Puligoundla, R. et al. A simple, convenient one-pot synthesis of $[1,2,4]$ triazolo/benzimidazolo quinazolinone derivatives by using molecular iodine. Tetrahedron Lett. 54, 2480-2483 (2013).

77. Kumari, K., Raghuvanshi, D. S. \& Nand Singh, K. An expeditious synthesis of tetrahydro-1,2,4- triazolo[5,1-b]quinazolin-8(4H)ones and dihydro-1,2,4-triazolo[1,5-a]pyrimidines. Organ. Prep. Proced. Int. 44, 460-466 (2012).

78. Heravi, M. M. et al. A three component one-pot procedure for the synthesis of $[1,2,4]$ triazolo/benzimidazolo-quinazolinone derivatives in the presence of $\mathrm{H}_{6} \mathrm{P}_{2} \mathrm{~W}_{18} \mathrm{O}_{62} \cdot 18 \mathrm{H}_{2} \mathrm{O}$ as a green and reusable catalyst. Mol. Divers. 12, 181-185. https://doi.org/10. 1007/s11030-008-9086-8 (2008).

79. Ding, Sh. et al. 1,1,3,3-Tetramethylguanidine immobilized on graphene oxide: A highly active and selective heterogeneous catalyst for Aldol reaction. Catal. Commun. 92, 5-9 (2017).

80. Wang, Y. et al. IR spectroscopy and theoretical vibrational calculation of the melamine molecule. J. Chem. Soc. 93, 3445-3451 (1997).

81. Yuan, X. et al. Combinatorial vibration-mode assignment for the FTIR spectrum of crystalline melamine: A strategic approach toward theoretical IR vibrational calculations of triazine-based compounds. J. Phys. Chem. A 120, 7427-7433. https://doi.org/10. 1021/acs.jpca.6b06015 (2016).

82. Costa, L. \& Camino, G. Thermal behaviour of melamine. J. Therm. Anal. 34, 423-429. https://doi.org/10.1007/BF01913181 (1988).

83. Mourad, A. F. E., Aly, A. A. \& Farag, H. H. Beshr Microwave assisted synthesis of triazoloquinazolinones and benzimidazoquinazolinones. Beilstein J. Organ. Chem. 3, 1-5 (2007).

84. Seyyedi, N., Shirini, F., Safarpoor, M., Langarudi, N. \& Jashnani, S. A simple and convenient synthesis of $[1,2,4]$ triazolo/benzimidazolo quinazolinone and $[1,2,4]$ triazolo[1,5-a]pyrimidine derivatives catalyzed by DABCO-based ionic liquids. J. Iran. Chem. Soc. 14, 1859-1867 (2017).

85. Krishnamurthy, G. \& Jagannath, K. V. Microwave-assisted silica-promoted solvent-free synthesis of triazoloquinazolinone and benzimidazoquinazolinones. J. Chem. Sci. 125, 807-811 (2013).

86. Alvim, H. G. O., da Silva Júnior, E. N. \& Neto, B. A. D. What do we know about multicomponent reactions? Mechanisms and trends for the Biginelli, Hantzsch, Mannich, Passerini and Ugi MCRs. RSC Adv. 4, 54282-54299. https://doi.org/10.1039/C4RA1 0651B (2014).

87. Sharma, M. G., Rajani, D. P. \& Patel, H. M. Green approach for synthesis of bioactive Hantzsch 1,4-dihydropyridine derivatives based on thiophene moiety via multicomponent reaction. R. Soc. Open Sci. 4, 170006. https://doi.org/10.1098/rsos.170006 (2017).

88. Dekamin, M. G. et al. Alginic acid: A highly efficient renewable and heterogeneous biopolymeric catalyst for one-pot synthesis of the Hantzsch 1,4-dihydropyridines. RSC Adv. 4, 56658-56664. https://doi.org/10.1039/C4RA11801D (2014)

89. Dekamin, M. G., Kazemi, E., Karimi, Z., Mohammadalipoor, M. \& Naimi-Jamal, M. R. Chitosan: An efficient biomacromolecule support for synergic catalyzing of Hantzsch esters by $\mathrm{CuSO}_{4}$. Int. J. Biol. Macromol. 93, 767-774. https://doi.org/10.1016/j.ijbio mac.2016.09.012 (2016).

90. Yarhosseini, M., Javanshir, S., Dekamin, M. G. \& Farhadnia, M. Tetraethylammonium 2-(carbamoyl)benzoate as a bifunctional organocatalyst for one-pot synthesis of Hantzsch 1,4-dihydropyridine and polyhydroquinoline derivatives. Monatshefte für Chemie Chem. Mon. 147, 1779-1787. https://doi.org/10.1007/s00706-016-1666-1 (2016).

\section{Acknowledgements}

The authors gratefully acknowledge the partial financial support from the Islamic Azad University, Rasht Branch, as well as the Research Councils of Iran University of Science and Technology (IUST), Tehran, Iran (Grant No:160/19108) and the University of Guilan, Rasht, Iran.

\section{Author contributions}

M.K. carried out the laboratory work, performed the synthetic experiments, prepared data analyses, participated in the design of the study and drafted the manuscript; M.G.D. and M.M. conceived of the study, designed the study, coordinated the study and helped draft the manuscript. M.G.D also completely revised the manuscript. M.N. coordinated the study and helped for interpretation of data. 


\section{Competing interests}

The authors declare no competing interests.

\section{Additional information}

Supplementary Information The online version contains supplementary material available at https://doi.org/ 10.1038/s41598-021-91463-1.

Correspondence and requests for materials should be addressed to M.G.D. or M.M.

Reprints and permissions information is available at www.nature.com/reprints.

Publisher's note Springer Nature remains neutral with regard to jurisdictional claims in published maps and institutional affiliations.

(c) (1) Open Access This article is licensed under a Creative Commons Attribution 4.0 International License, which permits use, sharing, adaptation, distribution and reproduction in any medium or format, as long as you give appropriate credit to the original author(s) and the source, provide a link to the Creative Commons licence, and indicate if changes were made. The images or other third party material in this article are included in the article's Creative Commons licence, unless indicated otherwise in a credit line to the material. If material is not included in the article's Creative Commons licence and your intended use is not permitted by statutory regulation or exceeds the permitted use, you will need to obtain permission directly from the copyright holder. To view a copy of this licence, visit http://creativecommons.org/licenses/by/4.0/.

(C) The Author(s) 2021 